\title{
Deriving polarization properties of desert-reflected solar spectra with PARASOL data
}

\author{
W. Sun ${ }^{1,3}$, R. R. Baize ${ }^{2}$, C. Lukashin ${ }^{2}$, and Y. $\mathbf{H u}^{2}$ \\ ${ }^{1}$ Science Systems and Applications, Inc., Hampton, VA 23666, USA \\ ${ }^{2}$ NASA Langley Research Center, Hampton, VA 23681, USA \\ ${ }^{3}$ Mail Stop 420, NASA Langley Research Center, Hampton, VA 23681, USA \\ Correspondence to: W. Sun (wenbo.sun-1@nasa.gov)
}

Received: 9 February 2015 - Published in Atmos. Chem. Phys. Discuss.: 23 March 2015

Revised: 18 June 2015 - Accepted: 2 July 2015 - Published: 15 July 2015

\begin{abstract}
One of the major objectives of the Climate Absolute Radiance and Refractivity Observatory (CLARREO) is to conduct highly accurate spectral observations to provide an on-orbit inter-calibration standard for relevant Earthobserving sensors with various channels. To calibrate an Earth-observing sensor's measurements with the highly accurate data from the CLARREO, errors in the measurements caused by the sensor's sensitivity to the polarization state of light must be corrected. For correction of the measurement errors due to the light's polarization, both the instrument's dependence on the incident polarization state and the onorbit knowledge of the polarization state of light as a function of observed scene type, viewing geometry, and solar wavelength are required. In this study, an algorithm for deriving the spectral polarization state of solar light from the desert is reported. The desert/bare land surface is assumed to be composed of two types of areas: fine sand grains with diffuse reflection (Lambertian non-polarizer) and quartz-rich sand particles with facets of various orientations (specular-reflection polarizer). The Adding-Doubling Radiative Transfer Model (ADRTM) is applied to integrate the atmospheric absorption and scattering in the system. Empirical models are adopted in obtaining the diffuse spectral reflectance of sands and the optical depth of the dust aerosols over the desert. The ratio of non-polarizer area to polarizer area and the angular distribution of the facet orientations are determined by fitting the modeled polarization states of light to the measurements at three polarized channels $(490,670$, and $865 \mathrm{~nm})$ by the Polarization and Anisotropy of Reflectances for Atmospheric Science instrument coupled with Observations from a Lidar (PARASOL). Based on this physical model of the
\end{abstract}

surface, the desert-reflected solar light's polarization state at any wavelength in the whole solar spectra can be calculated with the ADRTM.

\section{Introduction}

One of the major objectives of the Climate Absolute Radiance and Refractivity Observatory (CLARREO) (Wielicki et al., 2013) is to conduct highly accurate spectral observations to provide an on-orbit inter-calibration standard for relevant Earth-observing sensors with various channels. To calibrate an Earth-observing sensor's measurements with the highly accurate data from the CLARREO, errors in the measurements caused by the sensor's sensitivity to the polarization state of light must be corrected (Lukashin et al., 2013; Sun and Lukashin, 2013; Sun et al., 2015). For correction of the measurement errors due to light's polarization, both the instrument's dependence on the incident polarization state and the on-orbit knowledge of the polarization state of light as a function of observed scene type, viewing geometry, and solar wavelength are required. Empirical polarization distribution models (PDMs) (Nadal and Breon, 1999; Maignan et al., 2009) based on data from the Polarization and Anisotropy of Reflectances for Atmospheric Science instrument coupled with Observations from a Lidar (PARASOL) (Deschamps et al., 1994) may be used to correct radiometric bias (Lukashin et al., 2013). But these can only be done at three solar wavelengths (i.e., 490, 670, and $865 \mathrm{~nm}$ ) at which the PARASOL has reliable polarization measurements. Since the CLARREO is designed to measure solar spectra from 320 
to $2300 \mathrm{~nm}$ with a spectral sampling of $4 \mathrm{~nm}$ (Wielicki et al., 2013), which has potential to inter-calibrate space-borne sensors at nearly all of the solar wavelengths (Sun and Lukashin, 2013), the PDMs for the inter-calibration applications should be made as functions of every sampling wavelength of the CLARREO. Due to strong dependence of solar light's polarization on wavelength (Sun and Lukashin, 2013), the applicability of empirical PDMs based on only three channels of PARASOL polarization measurements will be very limited. In our previous studies (Sun and Lukashin, 2013; Sun et al., 2015), polarized solar radiation from the oceanatmosphere system is accurately modeled. Because the refractive index of water at solar spectra is well known (Thormählen et al., 1985), Sun and Lukashin (2013) actually can produce the PDMs for the ocean-atmosphere system at any solar wavelength. However, it is still a difficult problem to obtain spectral PDMs for other scene types. For scene types other than water bodies, although many studies have been conducted (Coulson et al., 1964; Egan, 1968, 1969, 1970; Wolff, 1975; Vanderbilt and Grant, 1985; Tamalge and Curran, 1986; Grant, 1987), no reliable surface reflection matrix such as that based on the Cox and Munk $(1954,1956)$ wave slope distribution models for oceans is available. For scene types dominated by diffuse reflection like fresh snow, grasslands or needleleaf trees/bushes, this may not be a serious problem. But for scene types like desert, snow crust/ice surfaces, or even broad-leaved trees, specular reflection is still significant (like what happens at the ocean surface) and polarization of the reflected light can be very strong, thus it needs to be accurately accounted for. For example, the PARASOL data show that the degree of polarization (DOP) of reflected light from clear-sky deserts can be $\sim 30 \%$. The broad-leaved trees also can reflect solar light with a DOP of $\sim 70 \%$. For a sensor with a sensitivity-to-polarization factor of only $\sim 1 \%$, its measurement for light with a DOP of $\sim 30$ and $\sim 70 \%$ will have relative errors of $\sim 0.3$ and $\sim 0.7 \%$, respectively, solely due to the polarization (Sun and Lukashin, 2013).

For bare soils and vegetation, Bréon et al. (1995) developed some simple methods to calculate the polarized reflectance from the surface. But these methods can only model the polarized reflectance, which is not suitable for deriving the full elements of the surface reflection matrix for coupling with the radiative transfer model to simulate all Stokes parameters of the reflected light at the top of the atmosphere (TOA). Our objective for this study is to model the PDMs, which are the degree of polarization (DOP) and angle of linear polarization (AOLP) (Sun and Lukashin, 2013) of the reflected light at any solar wavelength. Polarized reflectance alone is insufficient for deriving the DOP and not usable for deriving the AOLP.

In this study, an algorithm for obtaining the spectral polarization state of solar light from the desert with the PARASOL data is developed. The method of deriving the polarization state of solar light from desert-atmosphere system at any wavelength with the PARASOL-measured polarized radiances at 490, 670, and $865 \mathrm{~nm}$ is reported in Sect. 2. Numerical results and discussions are presented in Sect. 3. A summary and conclusions are given in Sect. 4 .

\section{Method}

The polarization of reflected light is related to the surface roughness (Wolff, 1975) and to the size of reflecting elements (Egan, 1970). In this study, the desert/bare land surface is assumed to be composed of two types of areas: fine sand grains with diffuse reflection (Lambertian non-polarizer) and quartz-rich sand particles with facets of various orientations (specular-reflection polarizers). The desert surface light reflection matrix is obtained based on mixed effects of the two types of areas. Similar to the treatment for rough-ocean surfaces (e.g., Sun and Lukashin, 2013), the desert surface reflection matrix with $4 \times 4$ elements is calculated as

$$
\begin{aligned}
& \mathbf{R}_{0}\left(\theta_{\mathrm{s}}, \theta_{\mathrm{v}}, \phi\right)= \\
& \quad f \mathbf{R}_{\mathrm{L}}+(1-f) \frac{\pi \mathbf{M}\left(\theta_{\mathrm{s}}, \theta_{\mathrm{v}}, \phi\right)}{4 \cos ^{4} \beta \cos \theta_{\mathrm{s}} \cos \theta_{\mathrm{v}}} P\left(Z_{x}, Z_{y}\right),
\end{aligned}
$$

where $\theta_{\mathrm{s}}, \theta_{\mathrm{v}}$, and $\phi$ denote solar zenith angle, viewing zenith angle, and relative azimuth angle (RAZ) of the reflected light, respectively. The fraction of Lambertian area is denoted as $f$. $\mathbf{R}_{\mathbf{L}}$ is the reflection matrix of Lambertian reflector, with the reflectance as the only nonzero element. The $4 \times 4$ elements of $\mathbf{M}\left(\theta_{\mathrm{s}}, \theta_{\mathrm{v}}, \phi\right)$ for each quartz-rich sand particle facet orientation are calculated in the same way as in Mishchenko and Travis (1997) based on the Fresnel laws. $P\left(Z_{x}, Z_{y}\right)$ is the quartz-rich sand-facet orientation probability distribution as a function of the surface roughness. Assuming the desert is a stationary sand "ocean" with quartz-rich sand-particle facets as specular-reflection "waves" and Lambertian reflection sand grains as "foams", we can adopt the formula given in Cox and Munk (1956) for $P\left(Z_{x}, Z_{y}\right)$ as

$$
P\left(Z_{x}, Z_{y}\right)=\frac{1}{\pi \sigma^{2}} \exp \left(-\frac{Z_{x}^{2}+Z_{y}^{2}}{\sigma^{2}}\right),
$$

where $\sigma$ denotes the roughness parameter of the desert surface, and

$$
\begin{aligned}
& Z_{x}=\frac{\partial Z}{\partial x}=\frac{\sin \theta_{\mathrm{v}} \cos \phi-\sin \theta_{\mathrm{s}}}{\cos \theta_{\mathrm{v}}+\cos \theta_{\mathrm{s}}}, \\
& Z_{y}=\frac{\partial Z}{\partial y}=\frac{\sin \theta_{\mathrm{v}} \sin \phi}{\cos \theta_{\mathrm{v}}+\cos \theta_{\mathrm{s}}} .
\end{aligned}
$$

In Eqs. (2) to (4), $Z$ denotes the height of the surface. In Eq. (1), $\beta$ is the tilting angle of a sand facet, and $\tan \beta=$ $\sqrt{Z_{x}^{2}+Z_{y}^{2}}$. 


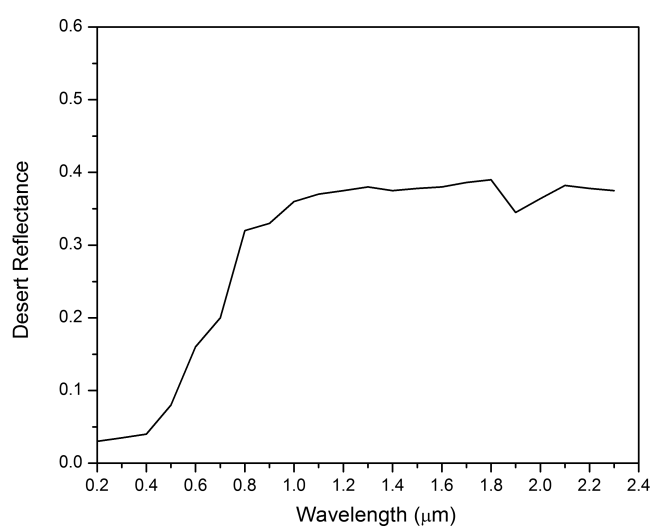

Figure 1. Empirical spectral reflectance of the desert from analysis of data in Aoki et al. (2002), Sadiq and Howari (2009), Bowker et al. (1985), and Koelemeijer et al. (2003), scaled by the PARASOL measurements.

The polarization of reflected solar radiation from the Earth-atmosphere system is the result of both the surface reflection and the scattering by molecules and particles in the atmosphere. In this study, the Adding-Doubling RadiativeTransfer Model (ADRTM) (Sun and Lukashin, 2013) is applied to integrate the atmospheric absorption and scattering with the desert surface reflection. To get the reflection matrix elements of the desert with Eq. (1), we must obtain four unknown quantities in advance: $f, \sigma, \mathbf{R}_{\mathbf{L}}$, and the refractive index of quartz-rich sand. In this study, the refractive index of quartz-rich sand is assumed to be that of fused silica as a function of solar wavelength (Malitson, 1965):

$$
\begin{aligned}
n^{2}-1 & =\frac{0.6961663 \lambda^{2}}{\lambda^{2}-(0.0684043)^{2}}+\frac{0.4079426 \lambda^{2}}{\lambda^{2}-(0.1162414)^{2}} \\
& +\frac{0.8974794 \lambda^{2}}{\lambda^{2}-(9.896161)^{2}},
\end{aligned}
$$

where $n$ is the real refractive index of the silica and $\lambda$ denotes the solar wavelength in micrometers $(\mu \mathrm{m})$. In this study, to account for the impurity absorption in the quartz-rich sands, we assume the imaginary part of the sand refractive index to be 0.02 . This assumption of sand's imaginary refractive index could have a small effect on the modeled total reflectance from the desert, but it has little effect on the DOP and AOLP calculations. However, $f, \sigma$, and $\mathbf{R}_{\mathbf{L}}$ must be obtained from observations for the desert. In this study, the spectral structure of the Lambertian reflectance of desert $R_{\mathrm{L}}^{0}(\lambda)$ for wavelength longer than $800 \mathrm{~nm}$ is based on the analysis of data in Aoki et al. (2002) and Sadiq and Howari (2009) for desert reflectance in the Taklimakan Desert and the southeast of Qatar, respectively. For wavelengths shorter than $800 \mathrm{~nm}$, the spectral structure of $R_{\mathrm{L}}^{0}(\lambda)$ is determined by an analysis of data in Aoki et al. (2002), Sadiq and Howari (2009), Bowker et al. (1985), and Koelemeijer et al. (2003). This spectral reflectance structure multiplied with a scale factor $\alpha$ is then
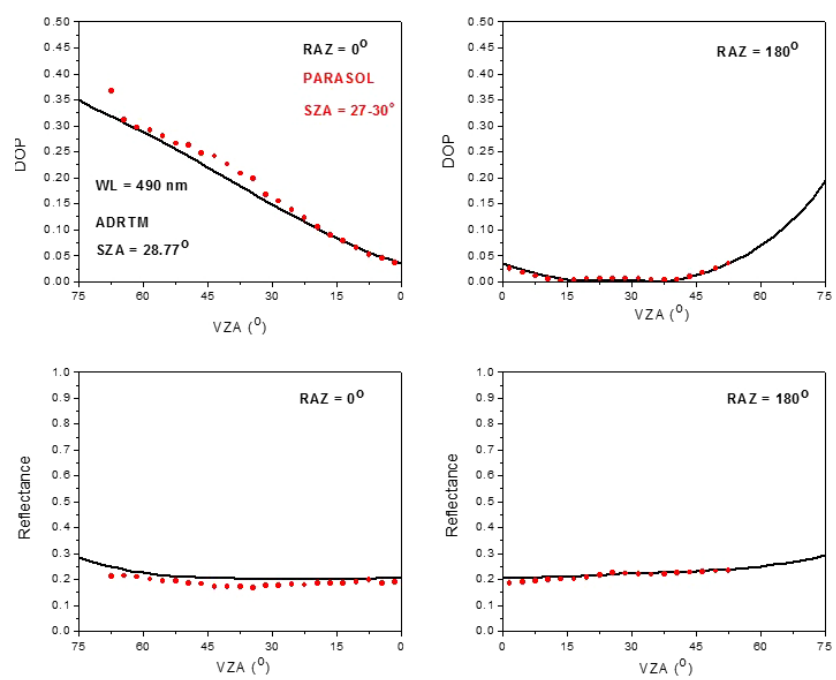

Figure 2. Comparison of the modeled DOP and reflectance of desert-reflected solar light at relative azimuth angles (RAZs) of 0 and $180^{\circ}$ with those from the PARASOL data at the wavelength of $490 \mathrm{~nm}$. The solar zenith angle (SZA) is $28.77^{\circ}$ in the modeling. The SZA is in the bin of $27-30^{\circ}$ for the PARASOL data.
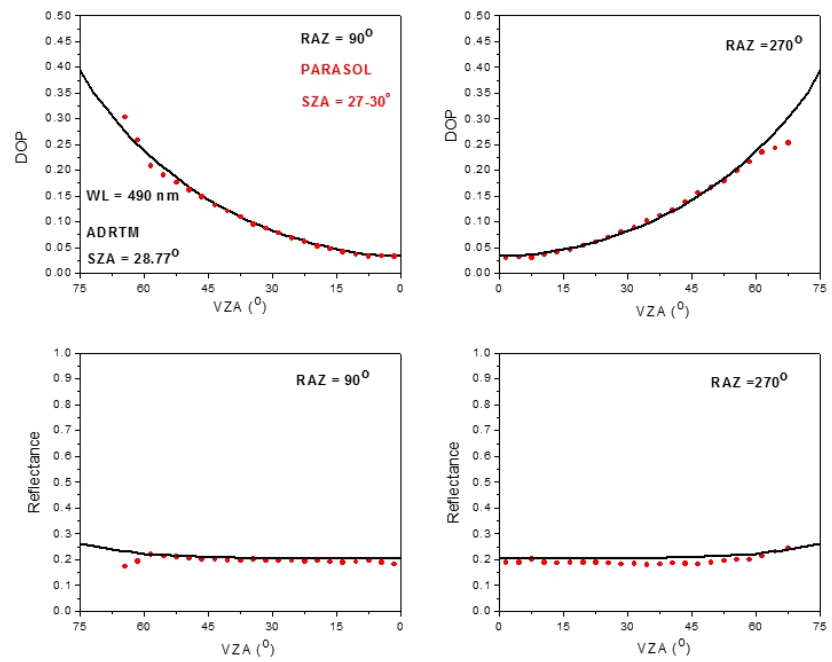

Figure 3. Same as in Fig. 2 but at RAZs of 90 and $270^{\circ}$.

entered in the ADRTM, and on the condition of $f=1.0$ and at a solar zenith angle of $28.77^{\circ}$ the solar reflectances at the wavelength of 490,670 , and $865 \mathrm{~nm}$ from the ADRTM and those from the 24-day mean of the PARASOL measurements are compared. By varying the scale factor $\alpha$, we can make the reflectance at wavelengths of 490,670, and $865 \mathrm{~nm}$ from the ADRTM close to those from the PARASOL data. The resul$\operatorname{tant} \alpha R_{\mathrm{L}}^{0}(\lambda)$ is the reflectance of the Lambertian desert area, which as the first element of the $\mathbf{R}_{\mathbf{L}}$ is linearly extrapolated to the CLARREO solar wavelength limit of $320 \mathrm{~nm}$. The empirical spectral reflectance of the desert from this process is displayed in Fig. 1. 

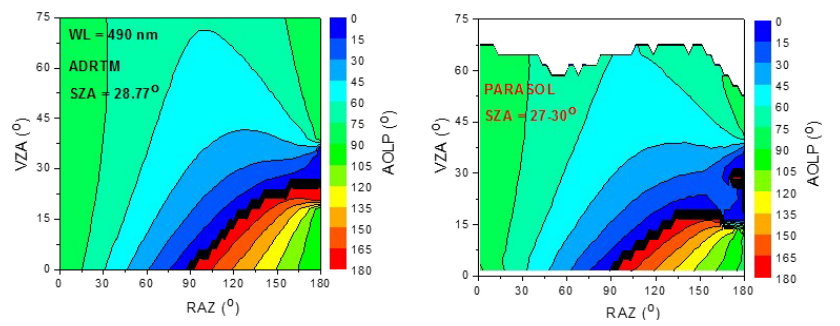

Figure 4. Comparison of the modeled AOLP of desert-reflected solar light with those from the PARASOL data at the wavelength of $490 \mathrm{~nm}$. The SZA is $28.77^{\circ}$ in the modeling. The SZA is in the bin of $27-30^{\circ}$ for the PARASOL data.
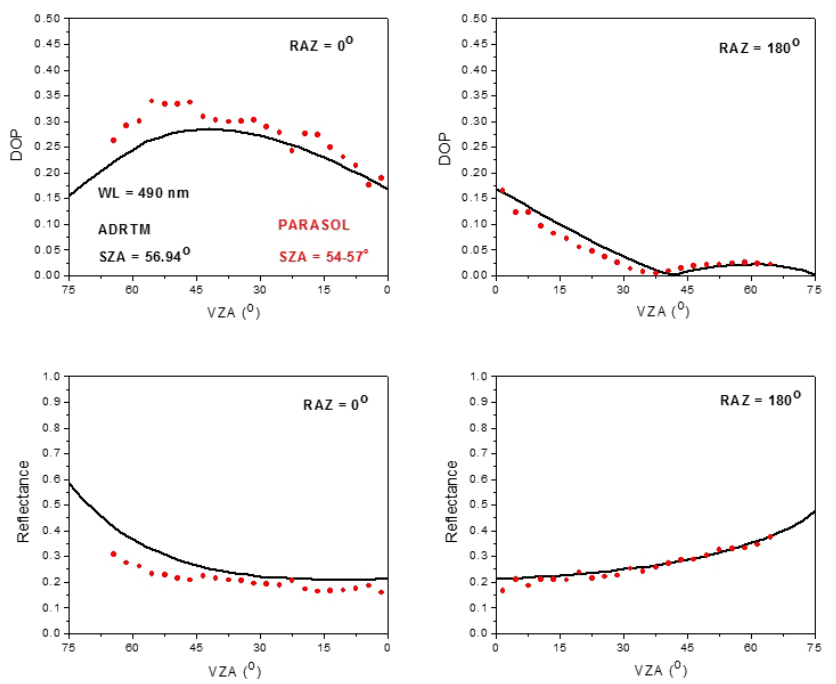

Figure 5. Comparison of the modeled DOP and reflectance of desert-reflected solar light at RAZs of 0 and $180^{\circ}$ with those from the PARASOL data at the wavelength of $490 \mathrm{~nm}$. The SZA is $56.94^{\circ}$ in the modeling. The SZA is in the bin of $54-57^{\circ}$ for the PARASOL data.

Since desert reflectance varies significantly with desert types (Otterman, 1981; Bowker et al., 1985; Dobber et al., 1998; Aoki et al., 2002; Koelemeijer et al., 2003), our empirical desert $\mathbf{R}_{\mathbf{L}}$ model may not be very representative. However, with the other two free parameters $f$ and $\sigma$ in the model, we may still approach the accurate PDMs (i.e., DOP and AOLP) even when $\mathbf{R}_{\mathbf{L}}$ has some difference from true values in practice.

In this study, the ADRTM (Sun and Lukashin, 2013) is applied for calculation of the Stokes parameters of the reflected light from the desert-atmosphere system. The US Standard Atmosphere (1976) is applied in the calculations. Gas absorption coefficients from the $k$ distribution treatment (Kato et al., 1999) of the spectral data from the Line-by-Line Radiative Transfer Model (LBLRTM) (Clough et al., 1992; Clough and Iacono, 1995) using the MODTRAN 3 data set (Kneizys et al., 1988) is used. Ozone absorption coefficients are taken from the ozone cross-section table provided by the
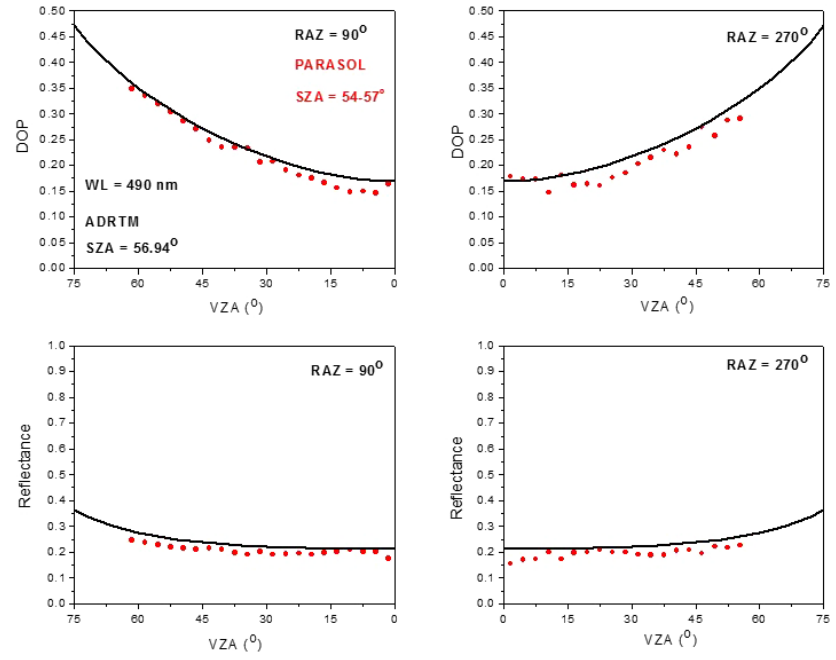

Figure 6. Same as in Fig. 5 but at RAZs of 90 and $270^{\circ}$.
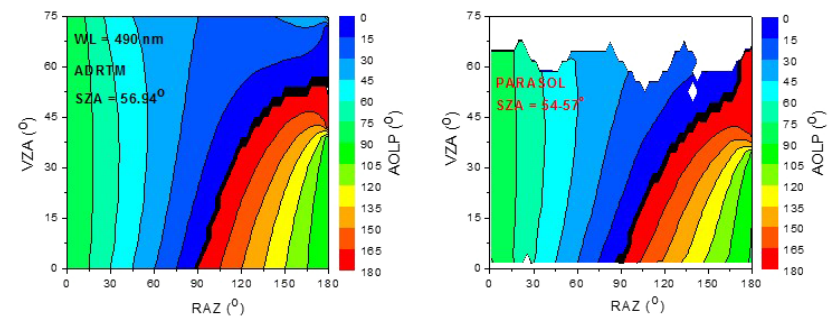

Figure 7. Comparison of the modeled AOLP of desert-reflected solar light with those from the PARASOL data at the wavelength of $490 \mathrm{~nm}$. The SZA is $56.94^{\circ}$ in the modeling. The SZA is in the bin of $54-57^{\circ}$ for the PARASOL data.

World Meteorological Organization (1985) for wavelengths smaller than $700 \mathrm{~nm}$. Molecular scattering optical thickness is from Hansen and Travis (1974). The scattering phase matrix elements of molecular atmosphere are based on the Rayleigh scattering solution with a depolarization factor of 0.03 (Hansen and Travis, 1974). Single-scattering properties of sand-dust aerosols are calculated using agglomerated debris particles with the discrete-dipole approximation (DDA) light-scattering model (Zubko et al., 2006, 2009, 2013). Twomode lognormal size distributions (Davies, 1974; Whitby, 1978; Reist, 1984; Ott, 1990; Porter and Clarke, 1997) are applied in calculation of the single-scattering properties of aerosols. A dust aerosol refractive index of $1.5+0.0 i$ is assumed in the modeling. An average aerosol optical depth (AOD) of the dust over the Morocco desert (Toledano et al., 2008) is adopted in this study:

$\mathrm{AOD}=0.2374 \lambda^{-0.2291}$,

where $\lambda$ is the solar wavelength in micrometers $(\mu \mathrm{m})$. Equation (6) shows that dust AOD decreases with the increase of wavelength. 

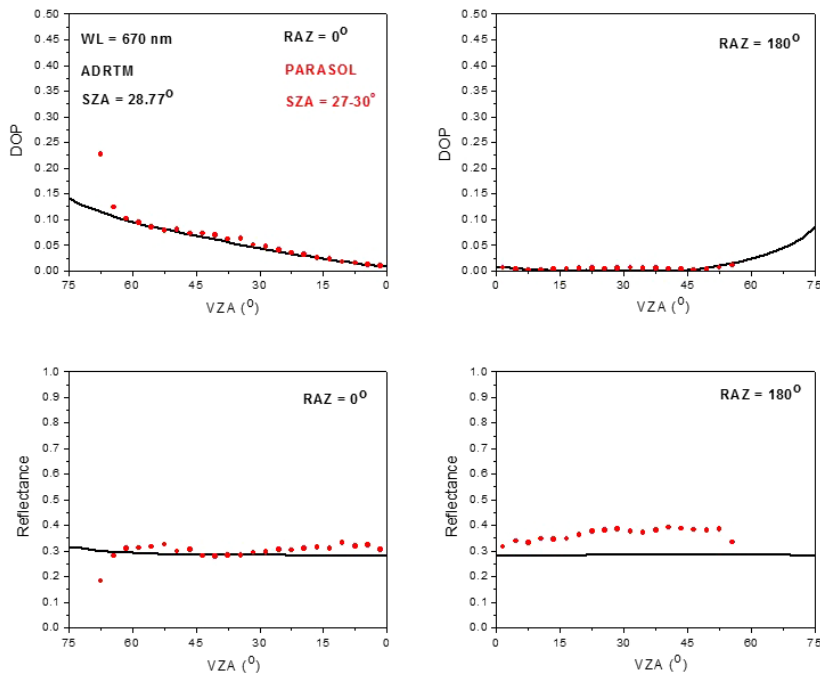

Figure 8. Comparison of the modeled DOP and reflectance of desert-reflected solar light at RAZs of 0 and $180^{\circ}$ with those from the PARASOL data at the wavelength of $670 \mathrm{~nm}$. The SZA is $28.77^{\circ}$ in the modeling. The SZA is in the bin of $27-30^{\circ}$ for the PARASOL data.
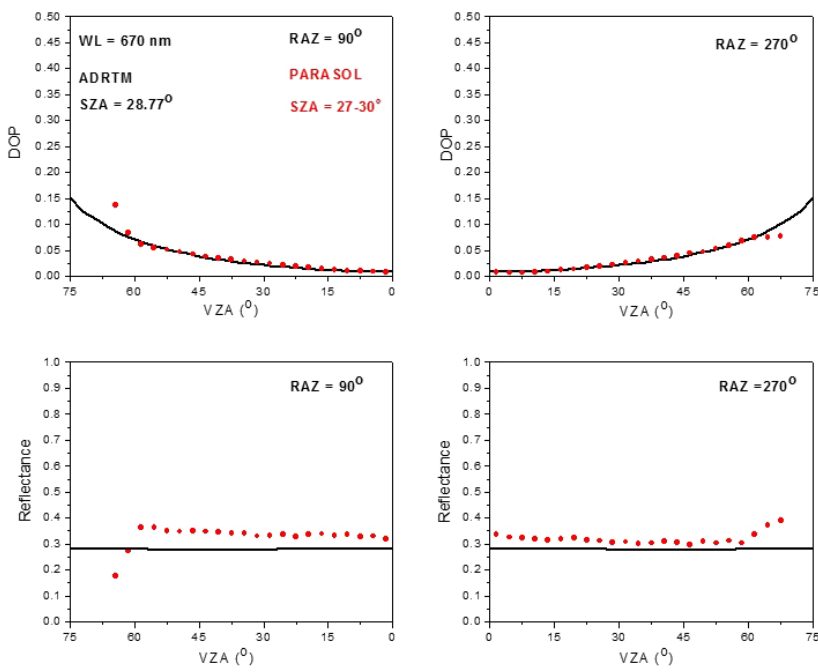

Figure 9. Same as in Fig. 8 but at RAZs of 90 and $270^{\circ}$.

In this study, the ratio of the non-polarizer area to polarizer area of the desert and the angular distribution of the quartzrich sand-particle facet orientations are determined by fitting the modeled polarization states of reflected light to the measurements at three polarized channels $(490,670$, and $865 \mathrm{~nm})$ of the PARASOL. By varying the two free parameters $f$ and $\sigma$ in the model, we calculated a lookup table of spectral DOP and AOLP as functions of $f$ and $\sigma$ for the desert. We then compared the modeled DOP and AOLP with those from the PARASOL data. The pair of $f$ and $\sigma$ that simultaneously produce similar DOP and AOLP to the PARASOL data at a solar zenith angle of $28.77^{\circ}$ and three polarized channels
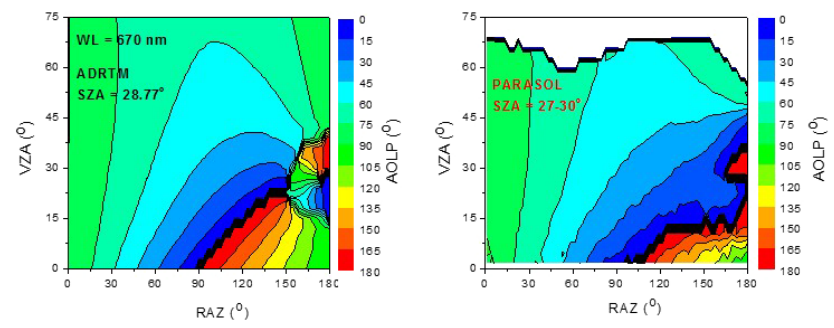

Figure 10. Comparison of the modeled AOLP of desert-reflected solar light with those from the PARASOL data at the wavelength of $670 \mathrm{~nm}$. The SZA is $28.77^{\circ}$ in the modeling. The SZA is in the bin of $27-30^{\circ}$ for the PARASOL data.
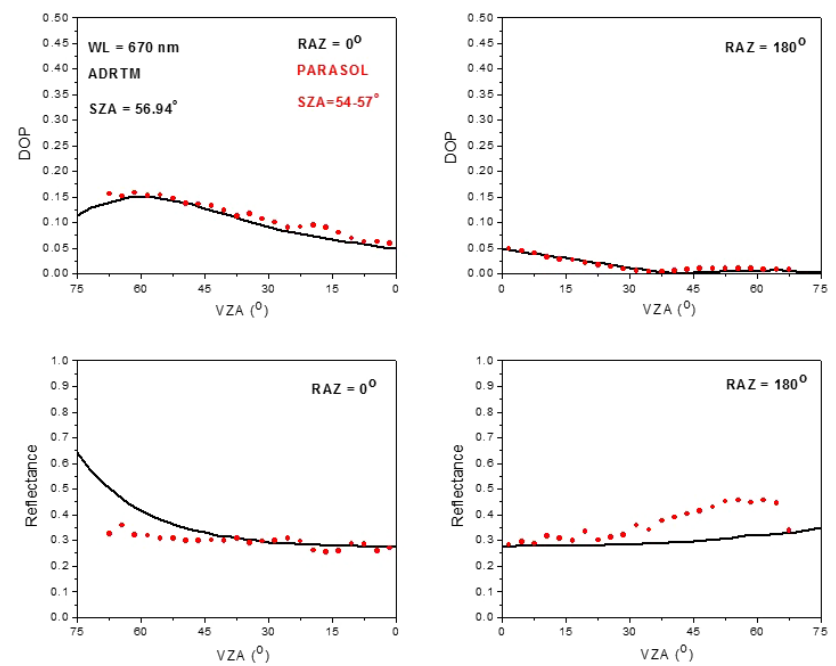

Figure 11. Comparison of the modeled DOP and reflectance of desert-reflected solar light at RAZs of 0 and $180^{\circ}$ with those from the PARASOL data at the wavelength of $670 \mathrm{~nm}$. The SZA is $56.94^{\circ}$ in the modeling. The SZA is in the bin of $54-57^{\circ}$ for the PARASOL data.

(490, 670, and $865 \mathrm{~nm}$ ) of the PARASOL are the retrieved values for the physical model of desert surface. In this retrieval, the PARASOL data are from the mean of 24-day measurements for global deserts. The 24 days of PARASOL data are taken from the first 2 days of each month across 2006. The retrieved $f$ and $\sigma$ values are then used to calculate the DOP and AOLP at any solar wavelengths and any solar zenith angles. This can produce the PDMs for clear-sky deserts. For deserts with clouds, it is straightforward to do the calculation by simply adding cloud layers in the ADRTM.

\section{Results}

In this study, the retrieved values of $f$ and $\sigma$ for the desert are 0.95 and 0.164 , respectively. These values are applied to the ADRTM to calculate the polarization properties of reflected solar spectra from the desert. Figures 2 to 4 show the modeled reflectance, DOP, and AOLP of reflected solar 

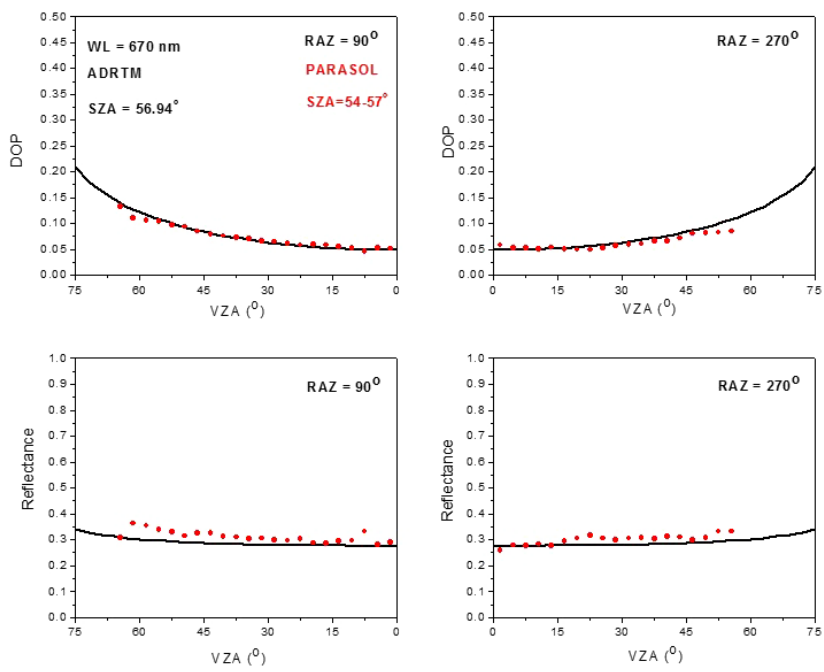

Figure 12. Same as in Fig. 11 but at RAZs of 90 and $270^{\circ}$.
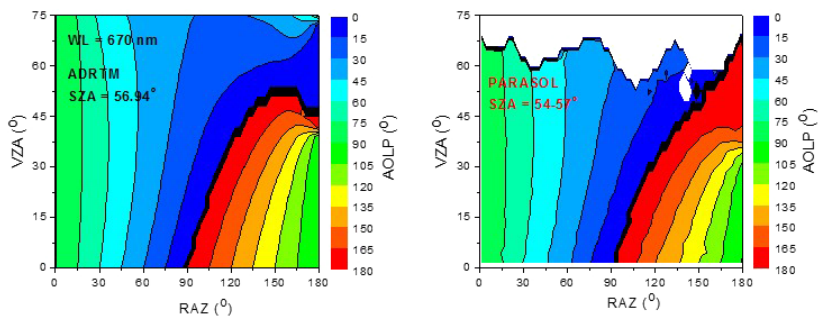

Figure 13. Comparison of the modeled AOLP of desert-reflected solar light with those from the PARASOL data at the wavelength of $670 \mathrm{~nm}$. The SZA is $56.94^{\circ}$ in the modeling. The SZA is in the bin of $54-57^{\circ}$ for the PARASOL data.

light from the desert at a wavelength of $490 \mathrm{~nm}$ and a solar zenith angle (SZA) of $28.77^{\circ}$ with those from the PARASOL data at a SZA bin of $27-30^{\circ}$. We can see that the model results are very close to the PARASOL data at nearly all viewing directions. The modeled DOP agrees very well with that from the PARASOL data, with differences smaller than $5 \%$. The AOLPs from the ADRTM and the PARASOL are also very similar, with only minor differences at viewing angles close to the back-scattering direction. The reflectance from the ADRTM with $f=0.95$ and $\sigma=0.164$ is also very close to that from the PARASOL, which is nearly Lambertian but a little larger in backward-reflecting directions. At a larger SZA of $56.94^{\circ}$, Figs. 5 to 7 show that the modeled reflectance, DOP, and AOLP are also very close to those from the PARASOL data, demonstrating that the retrieved desert physical property $f=0.95$ and $\sigma=0.164$ work well for solar angles other than the SZA of $28.77^{\circ}$, at which they are derived from the PARASOL measurements. From Figs. 2-7, we also can see that at the wavelength of $490 \mathrm{~nm}$ the desert has a strong polarization effect in the forward-reflecting direction. At a viewing zenith angle (VZA) of $60^{\circ}$, the DOP of the desert at $490 \mathrm{~nm}$ can reach $\sim 30 \%$, which means that, for
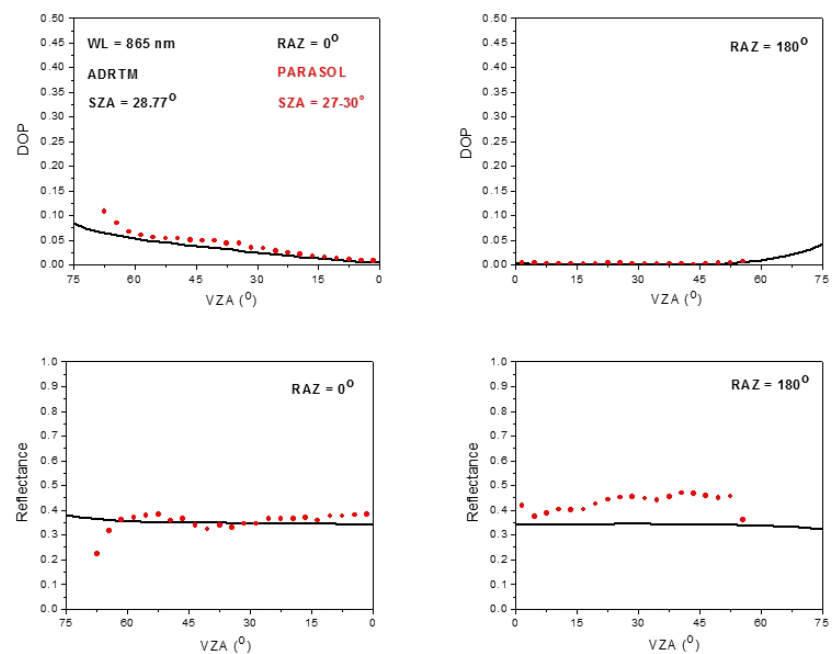

Figure 14. Comparison of the modeled DOP and reflectance of desert-reflected solar light at RAZs of 0 and $180^{\circ}$ with those from the PARASOL data at the wavelength of $865 \mathrm{~nm}$. The SZA is $28.77^{\circ}$ in the modeling. The SZA is in the bin of $27-30^{\circ}$ for the PARASOL data.
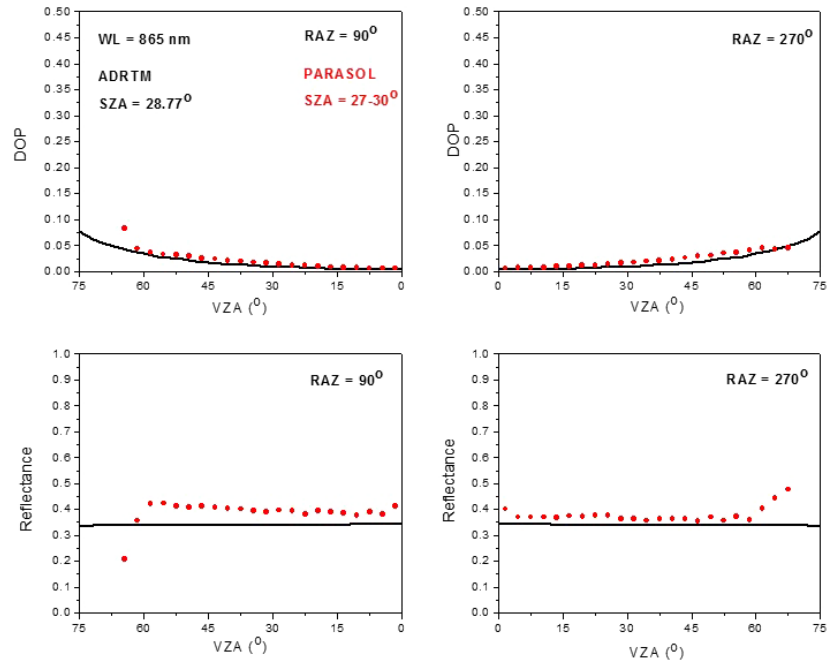

Figure 15. Same as in Fig. 14 but at RAZs of 90 and $270^{\circ}$.

a satellite sensor with only $\sim 1 \%$ polarization dependence, the desert polarization to sunlight can cause $\sim 0.3 \%$ error in spectral radiance measurement (Sun and Lukashin, 2013).

At a longer wavelength of $670 \mathrm{~nm}$, Figs. 8 to 13 show that the modeled DOP is very similar to the PARASOL data for different solar and viewing angles. The AOLP from the ADRTM shows some differences from that of the PARASOL in backward-reflecting directions. Particularly, Fig. 10 shows that the AOLP from the ADRTM has a pattern in the neighborhood of the backward-reflecting angle that is very similar to those for clouds reported in Sun and Lukashin (2013) and Sun et al. $(2014,2015)$. This likely is because the refractive index for dust aerosols in our modeling is assumed to be 1.5 

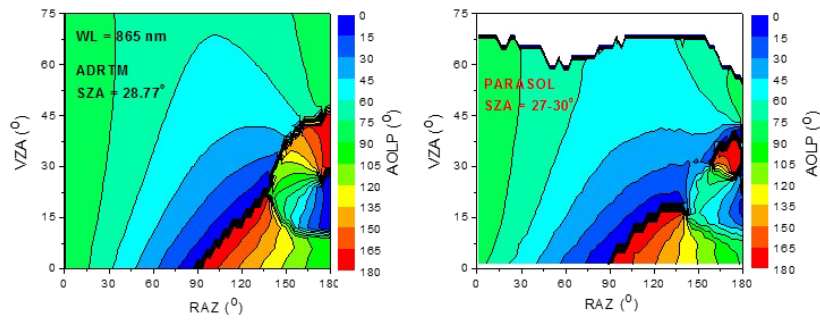

Figure 16. Comparison of the modeled AOLP of desert-reflected solar light with those from the PARASOL data at the wavelength of $865 \mathrm{~nm}$. The SZA is $28.77^{\circ}$ in the modeling. The SZA is in the bin of $27-30^{\circ}$ for the PARASOL data.
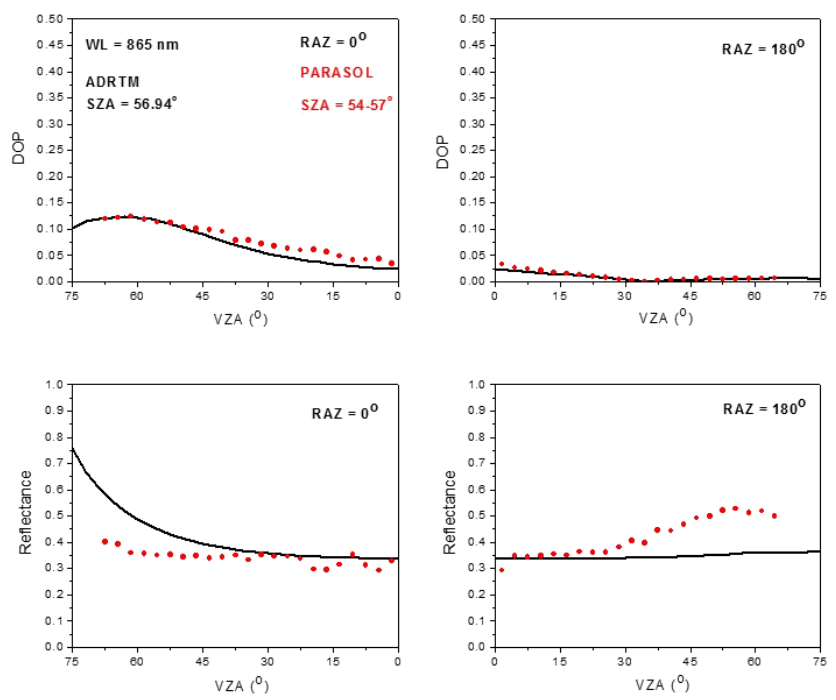

Figure 17. Comparison of the modeled DOP and reflectance of desert-reflected solar light at RAZs of 0 and $180^{\circ}$ with those from the PARASOL data at the wavelength of $865 \mathrm{~nm}$. The SZA is $56.94^{\circ}$ in the modeling. The SZA is in the bin of $54-57^{\circ}$ for the PARASOL data.

and the imaginary part is 0 . Under this condition, the dust particles are nonabsorbing crystals which have similar scattering properties to water droplets or ice crystals in clouds at the wavelength of $670 \mathrm{~nm}$. However, it is worth noting here that the errors in the AOLP from the ADRTM due to our assumptions for dust refractive index will only have a minor effect on the polarization correction accuracy. This is due to the fact that the DOPs at these observation angles are very small, and also that the AOLP errors in these observation angles actually will not result in any significant difference in polarization correction; i.e., $\mathrm{AOLP}=\sim 0^{\circ}$ and $\mathrm{AOLP}=\sim 180^{\circ}$ means the same to the satellite sensor. However, at $670 \mathrm{~nm}$, the PARASOL data for the desert show stronger reflectance in the backward-reflecting directions than in the forwardreflecting directions. This is significantly different from the ocean cases. Desert reflection of solar radiation is a complicated phenomenon that is neither Lambertian nor specular
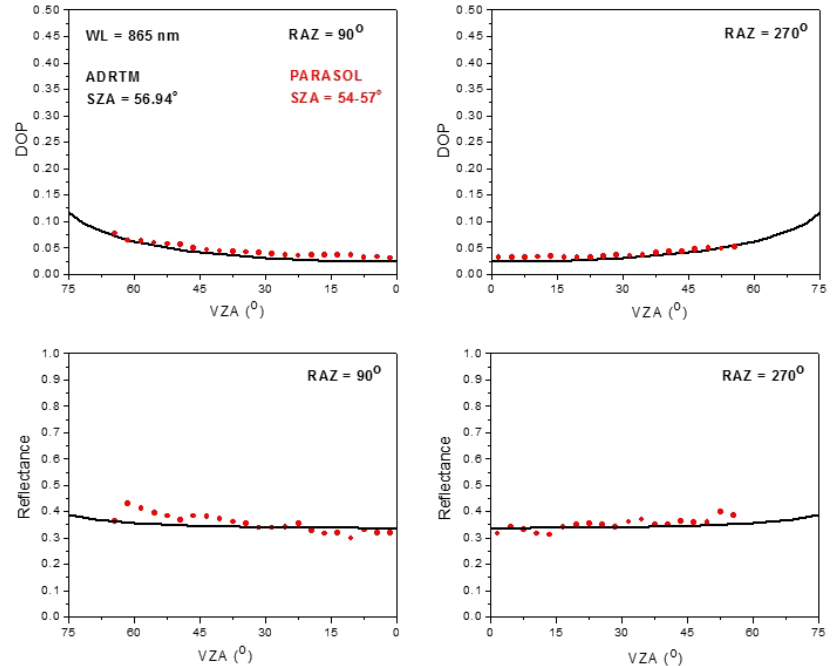

Figure 18. Same as in Fig. 17 but at RAZs of 90 and $270^{\circ}$.
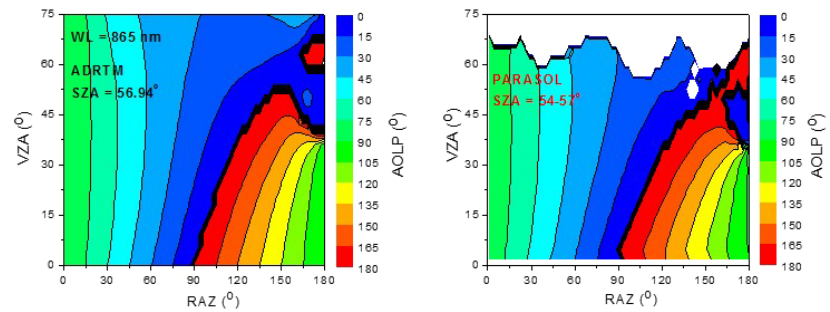

Figure 19. Comparison of the modeled AOLP of desert-reflected solar light with those from the PARASOL data at the wavelength of $865 \mathrm{~nm}$. The SZA is $56.94^{\circ}$ in the modeling. The SZA is in the bin of $54-57^{\circ}$ for the PARASOL data.

reflection. Thus, our simple approach here shows some difference in reflectance from the data. However, our objective for this study is to model the desert DOP accurately, and to model the desert AOLP accurately when the DOP is not trivial. Such modeling errors in the total reflectance are to be expected and not the concern of this study.

For an even longer wavelength of $865 \mathrm{~nm}$, Figs. 14 to 19 show that, similar to the cases for the wavelength of $670 \mathrm{~nm}$, the modeled DOP and AOLP are very similar to the PARASOL data. The PARASOL reflectance at $865 \mathrm{~nm}$ also shows significantly stronger reflectance in the backward-reflecting directions than in the forward-reflecting directions. Without knowing the proper reason for the desert reflectance angular feature, our modeling cannot capture this angular distribution of reflected light well. This is a topic deserving further study, in particular by researchers concerned with radiation energy budget studies.

Note here that it is not a surprise that we can get accurate modeling of the DOP and AOLP of reflected solar spectra from the desert as shown in Figs. 2-4, 8-10, and 1416 , for a solar zenith angle of $28.77^{\circ}$, since the parameters $f=0.95$ and $\sigma=0.164$ used in the modeling are retrieved 

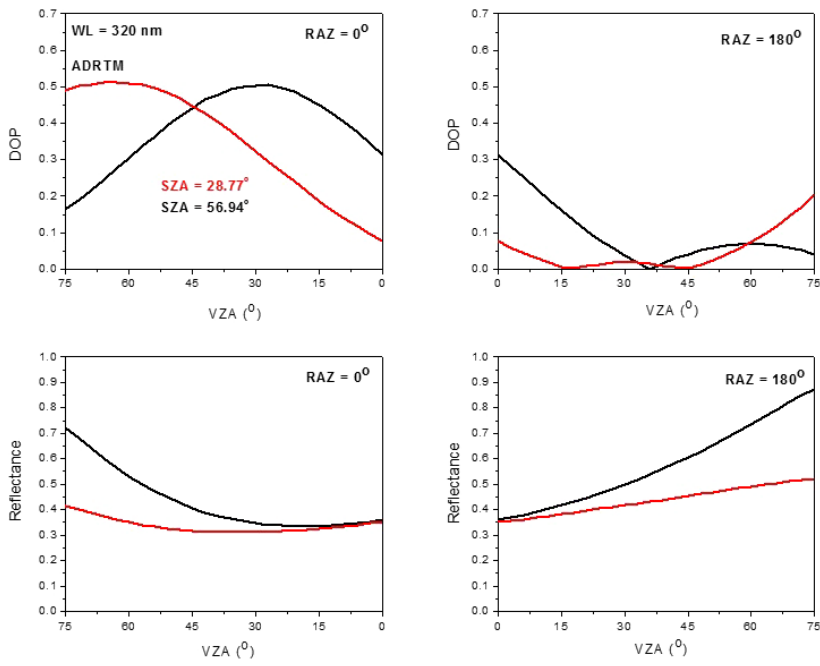

Figure 20. The modeled DOP and reflectance of desert-reflected solar light at RAZs of 0 and $180^{\circ}$ at the wavelength of $320 \mathrm{~nm}$. The SZA is 28.77 and $56.94^{\circ}$, respectively, in the modeling.
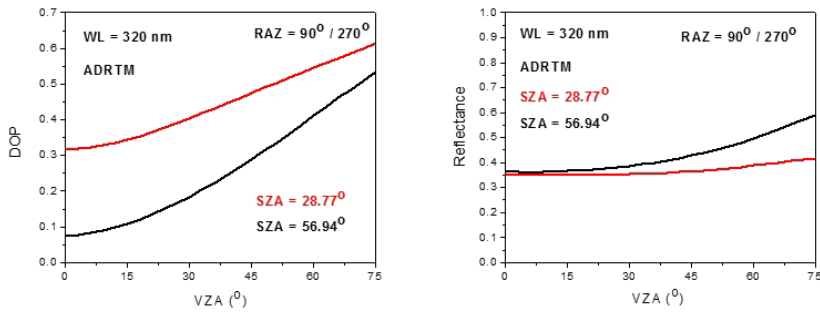

Figure 21. Same as in Fig. 20 but at RAZs of 90 and $270^{\circ}$.

from the PARASOL data at this solar zenith angle. To examine whether or not the desert surface physical parameters $(f$ and $\sigma$ ) from a specific solar zenith angle can be accurately applied to any other solar zenith angles, we modeled the polarized radiation from the desert-atmosphere system at a solar zenith angle of $56.94^{\circ}$ with the $f$ and $\sigma$ obtained at a solar zenith angle of $28.77^{\circ}$. These modeling results are compared with the PARASOL data in Figs. 5-7, 11-13, and 17-19. It is demonstrated that at all the three wavelengths of 490, 670, and $865 \mathrm{~nm}$ the DOP and AOLP from the ADRTM agree well with the PARASOL data in every case. These results show that the method can be applied to any other solar zenith angles once the desert surface physical parameters ( $f$ and $\sigma$ ) are obtained at a specific solar zenith angle.

As mentioned previously, the CLARREO is designed to measure solar spectra from 320 to $2300 \mathrm{~nm}$ with a spectral sampling of $4 \mathrm{~nm}$. To calibrate space-borne sensors with the CLARREO measurements in the solar spectra, the PDMs to correct polarization-induced errors in radiation measurement for the inter-calibration applications should be made as a function of every sampling wavelength of the CLARREO. Therefore, the modeling of the reflected solar radiation's polarization must be done over the range of solar wavelengths.
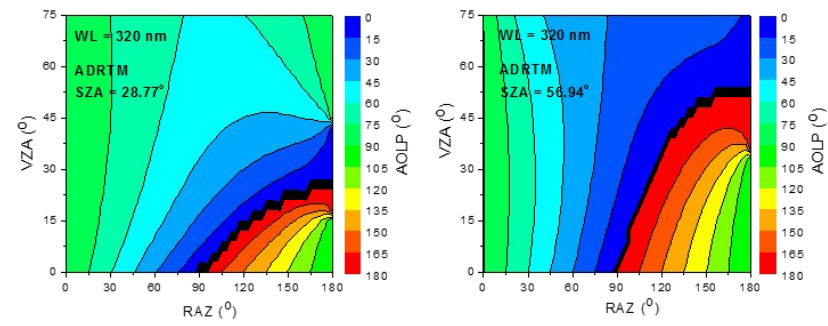

Figure 22. The modeled AOLP of desert-reflected solar light at the wavelength of $320 \mathrm{~nm}$. The SZA is 28.77 and $56.94^{\circ}$, respectively, in the modeling.
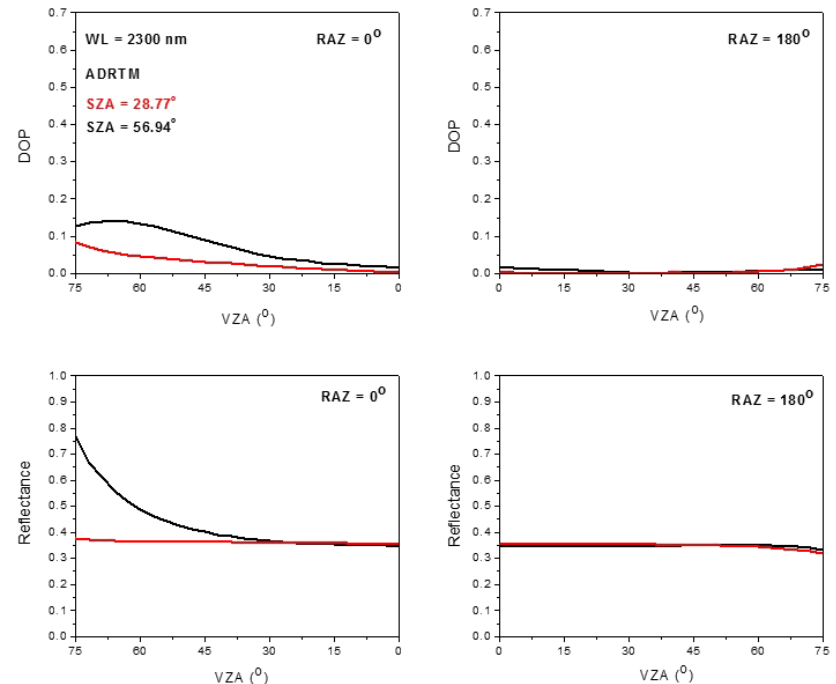

Figure 23. The modeled DOP and reflectance of desert-reflected solar light at RAZs of 0 and $180^{\circ}$ at the wavelength of $2300 \mathrm{~nm}$. The SZA is 28.77 and $56.94^{\circ}$, respectively, in the modeling.

Figures 20 to 25 show exemplary results for the modeling method to be applied to the wavelength limits (320 and $2300 \mathrm{~nm}$ ) of the CLARREO solar measurements at different solar zenith angles. It is shown that at short wavelengths the polarization from desert regions can be very strong, $\sim 50 \%$. However, at long wavelengths, the polarization degree is only $\sim 10 \%$. But even a $\sim 10 \%$ degree of polarization could cause significant errors in radiance if the sensor's dependence on polarization is significant.

\section{Conclusions}

In this study, an algorithm for deriving the spectral polarization state of solar light reflected from the desert is reported. The desert/bare land surface is assumed to be composed of two types of areas: fine sand grains with diffuse reflection (Lambertian non-polarizer) and quartz-rich sand particles with facets of various orientations (specular-reflection polarizer). The ADRTM is applied to integrate the atmospheric absorption and scattering in the system. Empirical models are 

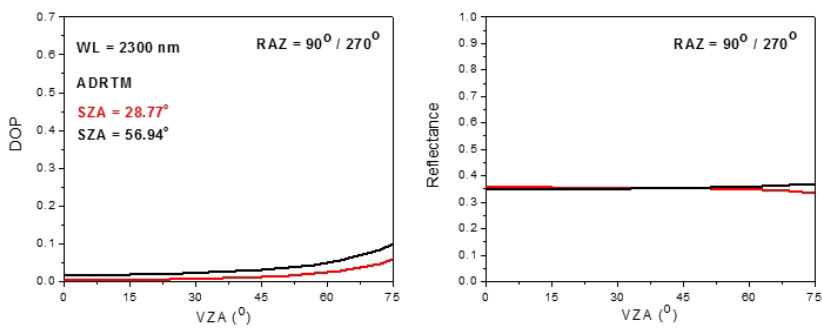

Figure 24. Same as in Fig. 23 but at RAZs of 90 and $270^{\circ}$.
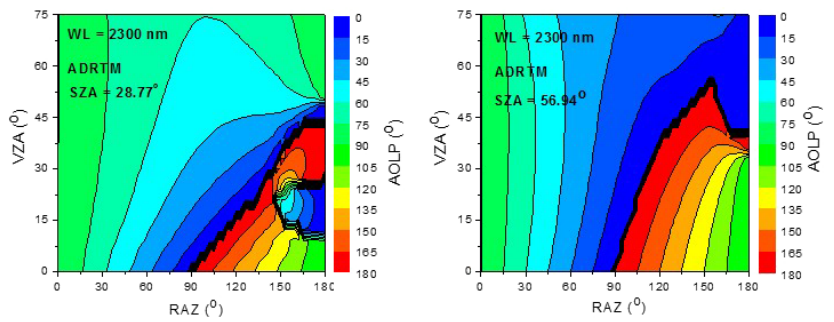

Figure 25. The modeled AOLP of desert-reflected solar light at the wavelength of $2300 \mathrm{~nm}$. The SZA is 28.77 and $56.94^{\circ}$, respectively, in the modeling.

adopted in obtaining the diffuse spectral reflectance of sands and the optical depth of the dust aerosols over the desert. The ratio of non-polarizer area to polarizer area and the angular distribution of the facet orientations are determined by fitting the modeled polarization states of light to the measurements at three polarized channels (490, 670, and $865 \mathrm{~nm})$ by the PARASOL. Based on this simple physical model of the surface, the polarization state of the desert-reflected solar radiation at any wavelength in the whole solar spectra can be calculated with the ADRTM. When more complicated surface models such as that considering deserts as semi-infinite particle layers are considered, it may improve the total reflectance modeling, but it will have little effect on polarization degree and angle of polarization calculation since polarization is mostly determined by single scattering at the top layer of the sand particles.

Acknowledgements. This work is supported by NASA's CLARREO mission. The authors thank Bruce A. Wielicki for this support and helpful discussions.

Edited by: J. Huang

\section{References}

Aoki, T., Mikami, M., and Liu, W.: Spectral albedos of desert surfaces and size distributions of soil particles measured around Qira and Aksu in the Taklimakan Desert, J. Arid Land Studies, 11, 259-266, 2002.
Bowker, D., Davis, R., Myrick, D., Stacy, K., and Jones, W.: Spectral reflectances of natural targets for use in remote sensing studies, NASA RP-1139, NASA Langley Research Center, Hampton, Virginia, USA, 1985.

Bréon, F.-M., Tanré, D., Lecomte, P., and Herman, M.: Polarized reflectance of bare soils and vegetation: measurements and models, IEEE T. Geosci. Remote Sens., 33, 487-499, 1995.

Clough, S. A. and Iacono, M. J.: Line-by-line calculations of atmospheric fluxes and cooling rates II: Application to carbon dioxide, ozone, methane, nitrous oxide, and the halocarbons, J. Geophys. Res., 100, 16519-16535, 1995.

Clough, S. A., Iacono, M. J., and Moncet, J.-L.: Line-by-line calculation of atmospheric fluxes and cooling rates: Application to water vapor, J. Geophys. Res., 97, 15761-15785, 1992.

Coulson, K. L., Gray, E. L., and Bouricius, G. M.: A study of the reflection and polarization characteristics of selected natural and artificial surfaces, Tech. Informat. Series, Rep. R64SD74, General Electric Co., Space Sciences Laboratory, Philadelphia, Pennsylvania, USA, 1964.

Cox, C. and Munk, W.: Measurement of the roughness of the sea surface from photographs of the sun's glitter, J. Opt. Soc. Am., 44, 838-850, 1954.

Cox, C. and Munk, W.: Slopes of the sea surface deduced from photographs of sun glitter, Bull. Scripps Inst. Oceanogr., 6, 401-488, 1956.

Davies, C.: Size distribution of atmospheric particles, Aerosol Sci., 5, 293-300, 1974

Deschamps, P. Y., Bréon, F. M., Leroy, M., Podaire, A., Bricaud, A., Buriez, J. C., and Sèze, G.: The POLDER mission: Instrument characteristics and scientific objectives, IEEE T. Geosci. Remote Sens., 32, 598-615, 1994.

Dobber, M., Goede, A., and Burrows, J.: Observations of the moon by the global ozone monitoring spectrometer experiment: radiometric calibration and lunar albedo, Appl. Optics, 37, 78327841, 1998.

Egan, W. G.: Aircraft polarimetric and photometric observations, Proc. 5th Int. Symp. Remote Sensing Env., 169-189, Environmental Research Institute of Michigan, Ann Arbor, Michigan, USA, 16-18 April, 1968.

Egan, W. G.: Polarimetric and photometric simulation of the Martian surface, Icarus, 10, 223-227, 1969.

Egan, W. G.: Optical stokes parameters for farm crops identification, Remote Sens. Environ., 1, 165-180, 1970.

Grant, L.: Diffuse and specular characteristics of leaf reflectance, Remote Sens. Environ., 22, 309-322, 1987.

Hansen, J. E. and Travis, L. D.: Light scattering in planetary atmospheres, Space Sci. Rev., 16, 527-610, doi:10.1007/BF00168069, 1974.

Kato, S., Ackerman, T. P., Mather, J. H., and Clothiaux, E. E.: The kdistribution method and correlated-k approximation for a shortwave radiative transfer model, J. Quant. Spectrosc. Ra., 62, 109121, doi:10.1016/S0022-4073(98)00075-2, 1999.

Kneizys, F. X., Shettle, E. P., Abreu, L. W., Chetwynd, J. H., Anderson, G. P., Gallery, W. O., Selby, J. E. A., and Clough, S. A.: Users guide to LOWTRAN 7, AFGL-TR-88-0177, Optical/Infrared Technology Division, Airforce Geophysics Division, Massachusetts, USA, 1988.

Koelemeijer, R., de Haan, J., and Stammes, P.: A database of spectral surface reflectivity in the range $335-772 \mathrm{~nm}$ derived from 
5.5 years of GOME observations, J. Geophys. Res., 108, 4070, doi:10.1029/2002JD002429, 2003.

Lukashin, C., Wielicki, B. A., Young, D. F., Thome, K., Jin, Z., and Sun, W.: Uncertainty estimates for imager reference intercalibration with CLARREO reflected solar spectrometer, IEEE T. Geosci. Remote. Sens., 51, 1425-1436, 2013.

Maignan, F., Breon, F.-M., Fedele, E., and Bouvier, M.: Polarized reflectances of natural surfaces: Spaceborne measurements and analytical modeling, Remote Sens. Environ., 113, 2642-2650, 2009.

Malitson, I. H.: Interspecimen comparison of the refractive index of fused silica, J. Opt. Soc. Am., 55, 1205-1208, doi:10.1364/JOSA.55.001205, 1965.

Mishchenko, M. I. and Travis, L. D.: Satellite retrieval of aerosol properties over the ocean using polarization as well as intensity of reflected sunlight, J. Geophys. Res., 102, 16989-17013, doi:10.1029/96JD02425, 1997.

Nadal, F. and Breon, F.-M.: Parameterization of surface polarized reflectance derived from POLDER spaceborne measurements, IEEE T. Geosci. Remote Sens., 37, 1709-1718, 1999.

Ott, W.: A physical explanation of the lognormality of pollutant concentrations, J. Air Waste Manage. Assoc., 40, 1378-1383, 1990.

Otterman, J.: Satellite and field studies of man's impact on the surface in arid regions, Tellus, 33, 68-77, 1981.

Porter, J. N. and Clarke, A. D.: Aerosol size distribution models based on in situ measurements, J. Geophys. Res., 102, 60356045, 1997.

Reist, P. C.: Introduction to Aerosol Science, McMillan, New York, 1984.

Sadiq, A. and Howari, F.: Remote sensing and spectral characteristics of desert sand from Qatar Peninsula, Arabian/Persian Gulf, Remote Sens., 1, 915-933, doi:10.3390/rs1040915, 2009.

Sun, W. and Lukashin, C.: Modeling polarized solar radiation from the ocean-atmosphere system for CLARREO intercalibration applications, Atmos. Chem. Phys., 13, 10303-10324, doi:10.5194/acp-13-10303-2013, 2013.

Sun, W., Videen, G., and Mishchenko, M. I.: Detecting super-thin clouds with polarized sunlight, Geophy. Res. Lett., 41, 688-693, doi:10.1002/2013GL058840, 2014.

Sun, W., Lukashin, C., Baize, R. R., and Goldin, D.: Modeling polarized solar radiation for CLARREO inter-calibration applications: Validation with PARASOL data, J. Quant. Spectrosc. Ra., 150, 121-133, 2015.

Tamalge, D. A. and Curran, P. J.: Remote sensing using partially polarized light, Int. J. Remote Sens., 7, 47-64, 1986.
Thormählen, I., Straub, J., and Grigull, U.: Refractive index of water and its dependence on wavelength, temperature, and density, J. Phys. Chem. Ref. Data, 14, 933-945, 1985.

Toledano, C., Wiegner, M., Garhammer, M., Seefeldner, M., Gasteiger, J., Muller, D., and Koepke, P.: Spectral aerosol optical depth characterization of desert dust during SAMUM 2006, Tellus B, 61, 216-228, 2008.

US Standard Atmosphere: National Oceanic and Atmospheric Administration, National Aeronautics and Space Administration, and United States Air Force: US Standard Atmosphere, NOAAS/T 76-1562, US Government Printing Office, Washington, D.C., 1976.

Vanderbilt, V. C. and Grant, L.: Plant canopy specular reflectance model, IEEE T. Geosci. Remote Sens., 23, 722-730, 1985.

Whitby, K.: The physical characteristics of sulfur aerosols, Atmos. Environ., 12, 135-159, 1978.

Wielicki, B. A., Young, D. F., Mlynczak, M. G., Thome, K. J., Leroy, S., Corliss, J., Anderson, J. G., Ao, C. O., Bantges, R., Best, F., Bowman, K., Brindley, H., Butler, J. J., Collins, W., Doelling, D. R., Dykema, J. A., Feldman, D. R., Fox, N., Holz, R. E., Huang, X., Huang, Y., Jennings, D. E., Jin, Z., Johnson, D. G., Jucks, K., Kato, S., Kirk-Davidoff, D. B., Knuteson, R., Kopp, G., Kratz, D. P., Liu, X., Lukashin, C., Mannucci, A. J., Phojanamongkolkij, N., Pilewskie, P., Ramaswamy, V., Revercomb, H., Rice, J., Roberts, Y., Roithmayr, C. M., Rose, F., Sandford, S., Shirley, E. L., Smith, Sr., W. L., Soden, B., Speth, P. W., Sun, W., Taylor, P. C., Tobin, D., and Xiong, X.: Climate absolute radiance and refractivity observatory (CLARREO): Achieving climate change absolute accuracy in orbit, B. Am. Meteorol. Soc., 94, 1519-1539, doi:10.1175/BAMS-D-12-00149.1, 2013.

Wolff, M.: Polarization of light reflected from rough planetary surface, Appl. Optics, 14, 1395-1405, 1975.

World Meteorological Organization: Atmospheric ozone 1985, Global ozone research and monitoring project, World Meteorological Organization (WMO) Report No. 16, Geneva, 1985.

Zubko, E., Shkuratov, Y., Kiselev, N. N., and Videen, G.: DDA simulations of light scattering by small irregular particles with various structure, J. Quant. Spectrosc. Ra., 101, 416-434, 2006.

Zubko, E., Kimura, H., Shkuratov, Y., Muinonen, K., Yamamoto, T., Okamoto, H., and Videen, G.: Effect of absorption on light scattering by agglomerated debris particles, J. Quant. Spectrosc. Ra., 110, 1741-1749, 2009.

Zubko, E., Muinonen, K., Munoz, O., Nousiainen, T., Shkuratov, Y., Sun, W., and Videen, G.: Light scattering by feldspar particles: Comparison of model agglomerate debris particles with laboratory samples, J. Quant. Spectrosc. Ra., 131, 175-187, 2013. 